\title{
Structures and Stabilities of Alkaline Earth Metal Oxide Nanoclusters: A DFT Study
}

\author{
Prinka Batra, Ritu Gaba, Upasana Issar, and Rita Kakkar \\ Department of Chemistry, University of Delhi, Delhi-110 007, India \\ Correspondence should be addressed to Rita Kakkar; rkakkar@chemistry.du.ac.in
}

Received 29 March 2013; Accepted 28 July 2013

Academic Editors: F. Aquilante, M. Koyama, and T. Takayanagi

Copyright (C) 2013 Prinka Batra et al. This is an open access article distributed under the Creative Commons Attribution License, which permits unrestricted use, distribution, and reproduction in any medium, provided the original work is properly cited.

\begin{abstract}
The stability orders of a number of alkaline earth oxide cluster isomers $(\mathrm{MO})_{n}, \mathrm{M}=\mathrm{Mg}, \mathrm{Ca}, \mathrm{Sr}, \mathrm{Ba}$ and $1 \leq n \geq 6$ have been determined by means of density functional theory studies using the LDA-PWC functional. Among the candidate structures, the hexagonal-ring-based isomers and the slab shapes are found to display similar stabilities. Stacks of hexagonal (MO) $)_{3}$ rings are found to be the slightly preferred growth strategy among the $(\mathrm{MgO})_{6}$, isomers. In contrast, the slab structures are slightly preferred for the other alkaline metal oxide (MO) ${ }_{6}$ clusters. An explanation based on packing and aromaticity arguments has been proposed. This study may have important implications for modeling and understanding the initial growth patterns of small nanostructures of alkaline earth metals.
\end{abstract}

\section{Introduction}

In the last few years, considerable effort has been directed to the understanding of metallic and semiconductor clusters. Clusters are aggregates of atoms or molecules intermediate in size between individual atoms and bulk matter, and their studies provide an interesting way to develop materials with varying properties by changing size and shape. Hence, studies of cluster properties as a function of size have received prominence in recent years. While much progress has been made on clusters of metals and semiconductors, metal oxide particles are often considered to be bulk fragments. However, their structure and properties could be entirely different in small clusters [1-4].

In this work, we have performed a comparative study of the structures, stabilities, and properties of some alkaline earth metal oxides $\left((\mathrm{MgO})_{n},(\mathrm{CaO})_{n},(\mathrm{SrO})_{n}\right.$, and $\left.(\mathrm{BaO})_{n}\right)$. Magnesium oxide crystallizes in the rock-salt structure and has some typical semiconducting properties, such as wide valence band $(\sim 6 \mathrm{eV})$, large dielectric constant (9.8), and small exciton binding energy $(<0.1 \mathrm{eV})$. For bulk $\mathrm{MgO}$, the experimental value of the band gap is $7.8 \mathrm{eV}$ [5]. It is close to an ideal insulating ionic solid with a valence band structure dominated by the strong potential of the ionic cores. Studies of the electronic properties of $\mathrm{MgO}$ are motivated by its technological applications, such as in catalysis, microelectronics, and electrochemistry. Bulk $\mathrm{MgO}$ is relatively inert, but its reactivity is greatly enhanced in the nanoscale. The high surface area and the intrinsically high surface reactivity of $\mathrm{MgO}$ nanocrystals make these materials especially effective as adsorbents [6]. In fact, they have been called "destructive adsorbents" because of their tendency to adsorb and simultaneously destroy by bond breaking processes a series of toxic chemicals [6-9].

It is interesting to study a similar system like calcium oxide in order to assess whether those trends are a general feature of alkaline earth oxide clusters or not. From the theoretical point of view, $\mathrm{Ca}^{2+}$ is larger than $\mathrm{Mg}^{2+}$, so we can expect ionic size effects to play an important role in determining structural differences. Besides, $\mathrm{Ca}^{2+}$ is approximately six times as polarizable as $\mathrm{Mg}^{2+}$, and the polarizabilities of the oxide anions are also larger in $\mathrm{CaO}$ because the bonding is weaker than in $\mathrm{MgO}$. Calcium oxide also crystallizes in the close-packed "rock-salt" structure and is primarily an ionic material, with some degree of covalency in its bonding. It is considered as a prototype oxide from the theoretical point of view, with a wide band gap $(7.1 \mathrm{eV})$ [10] and a high dielectric constant (11.8). Furthermore, local density approximation band structure calculations predicted 
a half-metallic ferromagnetic ground state for $\mathrm{CaO}$ [11]. Nanocrystalline $\mathrm{CaO}$ is used as an absorbent to remove COD from paper mill effluent [12].

Barium oxide is an oxide with interesting electronic and structural properties. It is also a precursor to the ferroelectric perovskite oxide $\mathrm{BaTiO}_{3}$ and a component of the earth's mantle. Barium strontium oxide coated carbon nanotubes serve as field emitters [13].

Theoretical work on ionic materials has been centered mostly in the family of alkali metal halides, and studies of metal oxide clusters have been comparatively scarce, despite their importance in many branches of surface physics, such as heterogeneous catalysis or corrosion. The mass spectra and collision induced fragmentation data for stoichiometric $(\mathrm{MgO})_{n}^{+}$and $(\mathrm{CaO})_{n}^{+}$cluster ions have been reported $[14$, 15]. The mass spectra of $(\mathrm{CaO})_{n} \mathrm{Ca}^{2+}$ cluster ions [16] and experimental measurements of several singly and doubly ionized cluster ions of $\mathrm{MgO}$ and $\mathrm{CaO}$ by laser ionization timeof-flight mass spectrometry [17-20] have also been published. Simple ionic models based on phenomenological pair potentials have been used to explain the global trends found in these experiments [17-20]. Several $a b$ initio calculations on stoichiometric $\mathrm{MgO}$ clusters have been presented [21-32], but the growth of these clusters is still not well understood.

We aim to study the electronic properties of the clusters of these alkaline earth metal oxides using the density functional approach.

\section{Computational Details}

In the calculations reported in the paper, first-principles density functional (DF) calculations were performed using the DMol [5] code [33-36], available from Accelrys Inc. in the Materials Studio 3.2 package. The DFT calculations were carried out employing both the generalized gradient approximation (GGA) with the PW91 functional [37], as well as the local density approximation (LDA) with the PWC (Perdew-Wang local correlation) functional [38]. Hybrid functionals such as B3LYP, though more accurate for metal oxide dissociation energies, cannot be efficiently used with plane waves and are hence not useful for calculations on solid materials [39]. Our calculations employed numerical basis sets of double- $\zeta$ quality plus polarization functions (DNP) to describe the valence orbitals. This basis set is the numerical equivalent of the Gaussian basis, $6-31 \mathrm{G}^{* *}$. The cores of $\mathrm{Ba}^{2+}$ and $\mathrm{Sr}^{2+}$ were treated with the all-electron approach.

Complete geometry optimizations for all structures $[\mathrm{MO}]_{n} 1 \leq n \leq 6$ were carried out. The atomic positions were relaxed to achieve minimum energy, until the system energy converged to $2 \times 10^{-5} \mathrm{Ha}$ and the gradient to $0.004 \mathrm{Ha}^{-1}$. The SCF tolerance was set at $1 \times 10^{-5}$ and the maximum displacement at $0.005 \AA$. The binding energies (BEs), the highest occupied molecular orbital (HOMO)lowest unoccupied molecular orbital (LUMO) gaps, Fermi energies, and density of states were also computed. The reported binding energy values were corrected for zero-point vibrational energies.

\section{Results}

Various structures, including the slab, hexagonal, octagonal, ladder, and other types, were studied for various numbers of formula units of the four alkaline earth metal oxides. Various theoretical studies at different levels of calculations have been reported in the literature [1, 2, 29, 32, 40-42], but there is no clear consensus regarding the suitability of LDA, GGA, or hybrid functionals for calculations on metal oxide nanoclusters. We therefore first compared results for the $\mathrm{MgO}$ molecular form obtained by different methods with the experimental quantities. The calculated LDA-PWC, GGA-PW91, B3LYP [40, 41], and MP4 [40, 41] values for the binding energy are $3.69,3.22,2.03$, and $3.22 \mathrm{eV}$, respectively. The latter three fall short of the experimental value [43] of $3.57 \mathrm{eV}$. The LDA result is far superior to the other calculations, although its tendency to overbind is clear from the result. Similarly, the computed $\mathrm{Mg}-\mathrm{O}$ bond lengths are $1.743,1.767$, and $1.756 \AA$, respectively, for LDA-PWC, GGAPW91, and B3LYP $[40,41]$ calculations in comparison with the experimental $[30,31,43]$ value of $1.749 \AA$. Here, again, our LDA result shows the best correspondence with experiment. The calculated vibrational frequencies are $751 \mathrm{~cm}^{-1}$ (LDA) and $719 \mathrm{~cm}^{-1}$ (GGA), in comparison with the observed [43] value of $785 \mathrm{~cm}^{-1}$.

For $\mathrm{CaO}$, too, the LDA-PWC calculated binding energy $(5.08 \mathrm{eV})$ is in better agreement with the experimental [43] value of $4.76 \mathrm{eV}$ than the B3LYP/6-311G(2d) [40, 41] value $(4.28 \mathrm{eV})$. Though the GGA-PW91 value $(4.55 \mathrm{eV})$ is in slightly better agreement with experiment, the LDA Ca-O bond distance $(1.818 \AA$ ) is in excellent agreement with the experimental [43] value (1.822 $\AA$ ), while the GGA value is considerably larger (1.843 $\AA$ ), reflecting the tendency of GGA to underbind. In the rest of the paper, therefore, we report the LDA results, but we also offer comparison with our calculated GGA results.

\subsection{Stabilities of Structures}

$(\mathrm{MO})_{2}$ Where $\mathrm{M}=\mathrm{Mg}, \mathrm{Ca}, \mathrm{Sr}, \mathrm{Ba}$. The optimized structures are rhombus shaped and planar (Figure 1). The angle about the magnesiums is obtuse $\left(95.7^{\circ}\right)$ in $(\mathrm{MgO})_{2}$, indicating the overlap repulsion between the large oxygen ions in close proximity since the cation size is small. However, for $\mathrm{CaO}$, the bond angles are acute $\left(\angle \mathrm{OCaO}=86.4^{\circ}\right)$. The bond angle about the metal ion decreases with increasing atomic number of the metal ion $\left(\angle \mathrm{OSrO}=82.7^{\circ}, \angle \mathrm{OBaO}=79.3^{\circ}\right)$, in parallel with the increasing ionic radii of the metal ions. The metal radii for $\mathrm{Mg}, \mathrm{Ca}, \mathrm{Sr}$, and $\mathrm{Ba}$ are $1.60,1.97,2.15$, and $2.17 \AA$, respectively, whereas the radii for the corresponding $\mathrm{M}^{2+}$ cations are $0.65,0.97,1.15$, and $1.35 \AA$ [44]. The atomic and ionic radii of $\mathrm{O}$ and lattice $\mathrm{O}^{2-}$ are 0.66 and $1.40 \AA$, respectively. The optimized $\mathrm{M}-\mathrm{O}$ bond distances are 1.858 , 2.005, 2.140, and 2.277 $\AA$, respectively, for $\mathrm{M}=\mathrm{Mg}, \mathrm{Ca}, \mathrm{Sr}$, and $\mathrm{Ba}$, which are all smaller than the sum of the ionic radii of $\mathrm{M}^{2+}$ and $\mathrm{O}^{2-}$, indicating that these bonds are not purely ionic. In contrast, the observed $\mathrm{M}-\mathrm{O}$ bond distances in the ionic crystals of the metal oxides are 2.106, 2.405, 2.565, and 


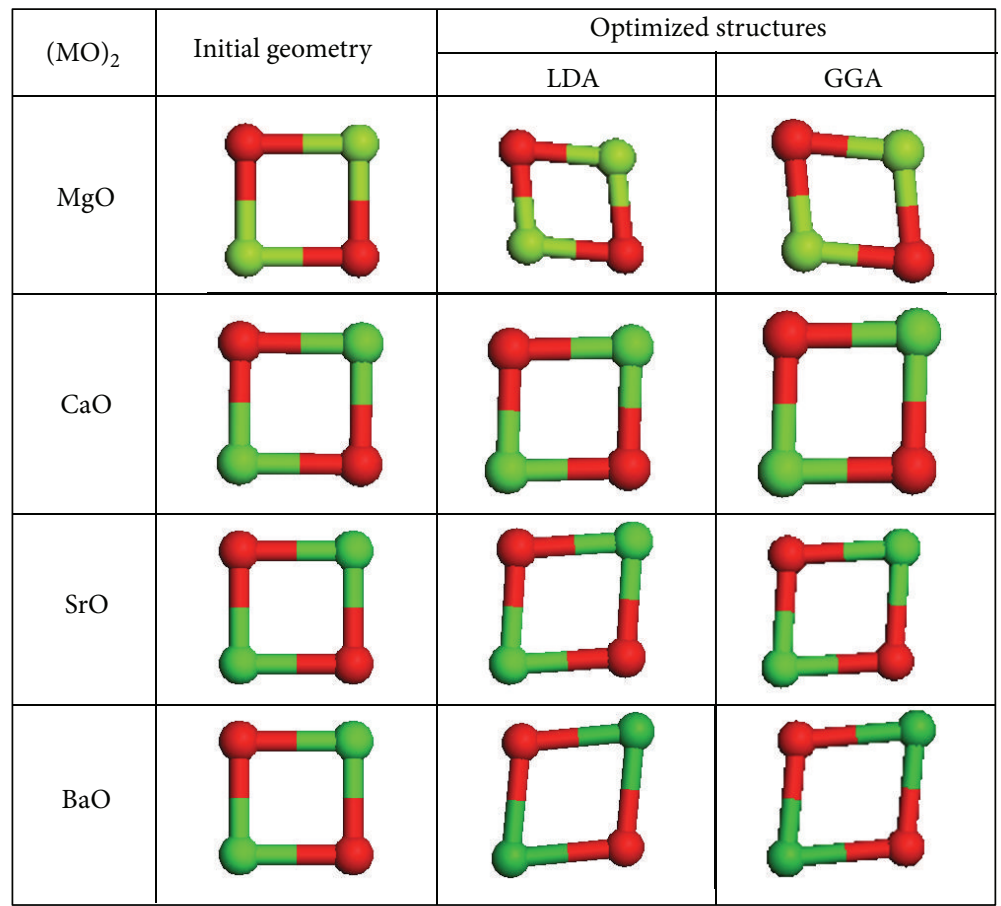

FIGURE 1: Optimized structures from LDA and GGA calculations, along with the initial geometries for the $(\mathrm{MO})_{2}$ systems.

TABLE 1: Calculated binding energies, HOMO-LUMO gaps, and Fermi energies (in eV) for $(\mathrm{MO})_{3}$ clusters.

\begin{tabular}{|c|c|c|c|c|c|c|c|}
\hline \multirow{2}{*}{ M } & \multirow{2}{*}{ Structure } & \multicolumn{2}{|c|}{ Binding energy } & \multicolumn{2}{|c|}{ HOMO-LUMO gap } & \multicolumn{2}{|c|}{ Fermi energy } \\
\hline & & LDA (PWC) & GGA (PW91) & LDA & GGA & LDA & GGA \\
\hline $\mathrm{Mg}$ & Hexagonal & -23.33 & -21.12 & 3.05 & 2.98 & -3.66 & -3.41 \\
\hline \multirow{2}{*}{$\mathrm{Ca}$} & Ladder & -25.61 & -23.13 & 1.79 & 1.70 & -2.02 & -1.80 \\
\hline & Hexagonal & -25.60 & -23.22 & 2.34 & 2.20 & -1.87 & -1.70 \\
\hline \multirow{2}{*}{$\mathrm{Sr}$} & Ladder & -25.63 & -23.29 & 1.87 & 1.69 & -1.92 & -1.80 \\
\hline & Hexagonal & -25.47 & -23.23 & 2.36 & 2.10 & -1.81 & -1.70 \\
\hline \multirow{2}{*}{$\mathrm{Ba}$} & Ladder & -26.93 & -24.60 & 2.03 & 1.88 & -1.76 & -1.66 \\
\hline & Hexagonal & -26.81 & -24.57 & 2.47 & 2.25 & -1.69 & -1.58 \\
\hline
\end{tabular}

$2.762 \AA$, respectively. The corresponding gas phase values [43] for the diatomic species are $1.749,1.822,1.920$, and $1.940 \AA$, respectively. The optimized $\mathrm{M}-\mathrm{O}$ bond distances are slightly closer to the gas phase values than to the ionic values. The calculated Mulliken charges on the metal ions are 0.930, 1.253, 0.959 , and 0.943 , respectively. In view of the fact that the metal and oxygen charges are close to +1 and -1 , respectively, the actual ionic radii are expected to lie between those for the neutral state and the divalent ions. The values of the partial charges indicate the slightly higher ionic character of $(\mathrm{CaO})_{2}$ compared to the other $(\mathrm{MO})_{2}$ systems.

Figure 1 gives the optimized structures for all the $(\mathrm{MO})_{2}$ moieties. In this figure, as well as all other figures, the metal ions are represented by green balls and the oxide ions by red balls.

$(\mathrm{MO})_{3}$ Where $\mathrm{M}=\mathrm{Mg}, \mathrm{Ca}, \mathrm{Sr}, \mathrm{Ba}$. Table 1 summarizes the results for the various $(\mathrm{MO})_{3}$ systems studied here. Here, $\mathrm{MO}$ stands for the four alkali metal oxides, $\mathrm{MgO}, \mathrm{CaO}, \mathrm{BaO}$, and
SrO. For $n=3$, the two possible structures, namely, ladder and hexagonal, were studied for all the metal oxides.

$(\mathrm{MgO})_{3}$. Both ladder and hexagonal ring starting structures optimized to a distorted hexagonal form with a binding energy of $-23.33 \mathrm{eV}$ (see Table 1 and Figure 2(a)). It is well known that $(\mathrm{MgO})_{3}$ ring structures are competitive building blocks in the growth of very small MgO clusters [29]. This result is also in agreement with our earlier calculations [22, 23] for $(\mathrm{MgO})_{12}$ clusters, which optimized to stacked rings from initial cubic rock salt structures.

In this ring structure (Figure 2(a)), the optimized (LDAPWC) bond angle about each oxygen is $103.9^{\circ}$, and that about each $\mathrm{Mg}$ is $136.1^{\circ}$. The $\mathrm{Mg}-\mathrm{O}$ bond distance is $1.819 \AA$. The increase of the $\angle \mathrm{OMgO}$ signifies repulsion between the oxygens. In fact, the $\mathrm{O}-\mathrm{O}$ distances are $3.374 \AA$, compared to $2.866 \AA$ for the $\mathrm{Mg}-\mathrm{Mg}$ distance. The $\mathrm{Mg}-\mathrm{O}$ bond orders are 0.872 , implying significant covalent character. The Mulliken charge on each oxygen is -0.915 . This signifies increased size 


\begin{tabular}{|l|l|l|l|}
\hline \multirow{2}{*}{ Shape } & \multirow{2}{*}{ Initial geometry } & \multicolumn{2}{|c|}{ Optimized structures } \\
\hline \multirow{2}{*}{ Ladder } & & LDA \\
\hline Hexagonal & &
\end{tabular}

(a)

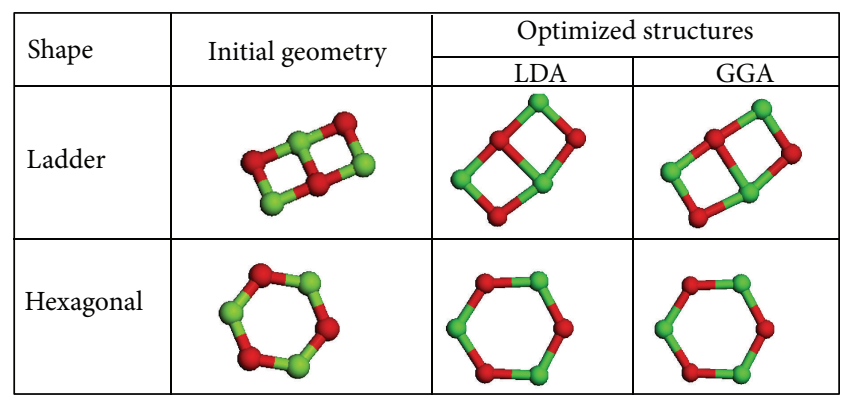

(b)

\begin{tabular}{|c|c|c|c|}
\hline \multirow{2}{*}{ Shape } & \multirow{2}{*}{ Initial geometry } & \multicolumn{2}{|c|}{ Optimized structures } \\
\hline & & LDA & GGA \\
\hline Ladder & & & \\
\hline Hexagonal & & & \\
\hline
\end{tabular}

(c)

Figure 2: (a) Optimized structures from LDA and GGA calculations, along with the initial geometries for the (MgO) ${ }_{3}$ system. (b) Optimized structures from LDA and GGA calculations, along with the initial geometries for the $(\mathrm{CaO})_{3}$ system. (c) Optimized structures from LDA and GGA calculations, along with the initial geometries for the $(\mathrm{SrO})_{3}$ system.

of the oxygen ion in the system relative to the oxygen atom. Therefore, the energy is lowered by keeping the oxide ions away from each other. The GGA-PW91 values are similar, although the computed $\mathrm{Mg}-\mathrm{O}$ bond distance is much larger $(1.843 \AA)$, reflecting the tendency of GGA to underbind atoms. This structure has a high band gap $(3.05 \mathrm{eV})$, which is much lower than that reported for bulk $\mathrm{MgO}$ [45-47].

$(\mathrm{CaO})_{3}$. For $(\mathrm{CaO})_{3}$, however, it was found that both initial structures optimized to different geometries. LDA calculations indicate that the ladder structure is slightly preferred, while GGA calculations predict a slight tilt in favor of the hexagonal structure $(\sim 0.1 \mathrm{eV})$. However, the energy differences are too small for one to make a definite statement regarding the relative stabilities. While the band gap for the hexagonal structure is $2.3 \mathrm{eV}$, that of the ladder structure is much smaller $(1.8 \mathrm{eV})$.

In the ladder structure, there are two types of atoms-the central ones having a coordination number of 3 , while the outer atoms having a coordination of 2 only and are more unsaturated. As a result, the Mulliken charge densities on the outer Ca atoms are 1.249, compared to 1.292 for the central Ca atom. Likewise, the terminal two-coordinate oxygens have a smaller negative charge $(-1.240)$, while the central one has a partial charge of -1.311 . The central bond length is also longer $(2.294 \AA)$ compared to the outer ones $(1.952 \AA)$. The increase in the central bond length can be understood in terms of the increased coordination of the central ions. The external field produced by the larger number of surrounding ions increases the ionic character of the central $\mathrm{Ca}-\mathrm{O}$ bond, which resembles the $\mathrm{Ca}-\mathrm{O}$ lattice limit $(2.405 \AA)$, while the terminal atoms are closer to the molecular limit (1.822 $\AA$ ). The bond orders are 0.837 and 0.610 , respectively. The $\mathrm{Ca}-\mathrm{O}$ bond lengths and bond orders are $2.059 \AA$ and 0.566 , respectively, in the $\mathrm{Ca}-\mathrm{O}-\mathrm{Ca}$ face, and $2.108 \AA$ and 0.662 in the $\mathrm{O}-\mathrm{Ca}-$ $O$ face. Again, this difference is due to the substantial ionic radius of $\mathrm{O}^{2-}$, and the $\mathrm{O}-\mathrm{Ca}-\mathrm{O}$ face has two of these ions, compared to only one in the opposite face.

Figure 2(b) depicts the optimized structures. It can be seen that the bond angles about the oxygens in the ladder structure are obtuse, while those about the calciums are acute.

$(\mathrm{SrO})_{3}$. For $(\mathrm{SrO})_{3}$, the ladder structure is preferred by $0.16 \mathrm{eV}$. In this structure (Figure 2(c)), the outer $\mathrm{Sr}-\mathrm{O}-\mathrm{Sr}$ angle is obtuse $\left(101.0^{\circ}\right)$, but the $\mathrm{O}-\mathrm{Sr}-\mathrm{O}$ bond angle is acute $\left(86.9^{\circ}\right)$. The shortest $\mathrm{Sr}-\mathrm{O}$ bond distances are the outer ones, that is, between two 2-coordinate sites (2.107 $\AA$ ), and the corresponding bond order is 1.128, while the longest bond is the central $\mathrm{Sr}_{3 \mathrm{c}}-\mathrm{O}_{3 \mathrm{c}}$ bond $(2.450 \AA$ ) with a bond order of only 0.397. The Mulliken charges on the atoms show a behavior similar to that observed for $(\mathrm{CaO})_{3}$; that is, the charges on $\mathrm{Sr}_{2 \mathrm{c}}, \mathrm{Sr}_{3 \mathrm{c}}, \mathrm{O}_{2 \mathrm{c}}$ and $\mathrm{O}_{3 \mathrm{c}}$ are 0.915, 1.055, -0.952 and -0.981, respectively.

$(\mathrm{BaO})_{3}$. For $(\mathrm{BaO})_{3}$, again, two different structures are obtained. The ladder structure is slightly preferred (by $0.12 \mathrm{eV}$; see Table 1). The Mulliken charges on the atoms show a behavior similar to that observed for $(\mathrm{CaO})_{3}$ and $(\mathrm{SrO})_{3}$; that is, the charges on $\mathrm{Ba}_{2 c}, \mathrm{Ba}_{3 c}, \mathrm{O}_{2 c}$, and $\mathrm{O}_{3 c}$ are 0.880, $1.035,-0.915$, and -0.965 , respectively. It is observed that the charge on the central (3-coordinate) metal ion decreases with increasing atomic number of the metal ion $(-1.311,-0.981$, 


\begin{tabular}{|l|l|l|l|}
\hline \multirow{2}{*}{ Shape } & \multirow{2}{*}{ Initial geometry } & \multicolumn{2}{|c|}{ Optimized structures } \\
\cline { 2 - 4 } Slab & LDA & GGA \\
\hline Octagonal & Ladder & &
\end{tabular}

(a)

\begin{tabular}{|l|l|l|}
\hline \multirow{2}{*}{ Shape } & \multirow{2}{*}{ Initial geometry } & \multicolumn{2}{c|}{ Optimized structures } \\
\hline \multirow{2}{*}{ Slab } & LDA & GGA \\
\hline Octagonal & Ladder &
\end{tabular}

(b)

\begin{tabular}{|l|l|l|}
\hline \multirow{2}{*}{ Shape } & \multirow{2}{*}{ Initial geometry } & \multicolumn{2}{|c|}{ Optimized structures } \\
\cline { 2 - 3 } Slab & LDA & GGA \\
\hline Octagonal & &
\end{tabular}

(c)

FIGURE 3: (a) Optimized structures from LDA and GGA calculations, along with the initial geometries for the ( $\mathrm{MgO})_{4}$ system. (b) Optimized structures from LDA and GGA calculations, along with the initial geometries for the $(\mathrm{CaO})_{4}$ system. (c) Optimized structures from LDA and GGA calculations, along with the initial geometries for the $(\mathrm{SrO})_{4}$ system. The $(\mathrm{BaO})_{4}$ system is similar.

and -0.965 , for ladder $(\mathrm{CaO})_{3},(\mathrm{SrO})_{3}$, and $(\mathrm{BaO})_{3}$, resp.), indicating the increasing involvement of the metal ion $\mathrm{d}$ orbitals and hence increasing covalency. As for $\mathrm{SrO}$, the inner $\mathrm{Ba}-\mathrm{O}$ bonds are longer $(2.512 \AA)$, and have a bond order of only 0.436 , but the outer $\mathrm{Ba}-\mathrm{O}$ bonds are shorter $(2.179 \AA)$, and the corresponding bond order is 1.160.

$(M O)_{4}$ Where $M=M g, C a, S r, B a$. In this case, three structures, namely, slab, octagonal, and ladder, were studied. Table 2 gives the calculated energies and the HOMO-LUMO gaps for the various structures. It is found that in all cases, the slab form is preferred over the other two. The energy differences are higher for this case, and the slab form is more emphatically preferred. Comparison of the calculated results is also made with B3LYP calculations [40, 41].

$(\mathrm{MgO})_{4}$. In the slab structure, all atoms are equivalent. We find that, from $(\mathrm{MgO})_{4}$ onward, three-dimensional structures are favored. $(\mathrm{MgO})_{4}$ has a cubic structure with rhombohedral distortion (Figure 3(a)), each atom being tricoordinated. The Mulliken charge on $\mathrm{Mg}$ is 0.930 , and all the $\mathrm{Mg}-\mathrm{O}$ bond orders are 0.570 . The bonding is therefore primarily ionic.

$(\mathrm{CaO})_{4}$. For $\mathrm{CaO}$, the slab structure is again preferred. Although both LDA and GGA indicate this preference, it is interesting to see that the optimized structures for the octagonal initial structure are different for the two cases (Figure 3(b)) and different from the initial ring structure, unlike the case of $(\mathrm{MgO})_{4}$ (Figure 3(a)). In the LDA case, the optimized structure consists of three fused rhombi, while the GGA optimized structure consists of fused six- and fourmembered rings.

$(\mathrm{SrO})_{4}$ and $(\mathrm{BaO})_{4} \cdot(\mathrm{SrO})_{4}$ and $(\mathrm{BaO})_{4}$ show behavior similar to $(\mathrm{CaO})_{4}$, except that both LDA and GGA give similar optimized structures for the octagonal form. For this reason, only the optimized structures for $(\mathrm{SrO})_{4}$ are shown in Figure 3(c).

An interesting result is that, although the slab structure is preferred in all cases, the next important structure is the ring for $(\mathrm{MgO})_{4}$, but for the other metal oxides, it is the ladder structure. Unlike $(\mathrm{MgO})_{4}$, the initial octagonal structure undergoes considerable distortion in all other cases.

$(\mathrm{MO})_{5}$ Where $\mathrm{M}=\mathrm{Mg}, \mathrm{Ca}, \mathrm{Sr}, \mathrm{Ba}$. The largest number of structures is possible in this case, namely, ladder, hexagonal, decagonal, chair, and many others (Table 3 ). In the case of $\mathrm{MgO}$, both LDA and GGA predict that the most stable structure is the chair form. Similar is the case for $\mathrm{CaO}$, that is, the chair form is the most stable structure, but in the case of 
TABle 2: Binding energies, HOMO-LUMO gaps, and Fermi energies (in eV) for $(\mathrm{MO})_{4}$ clusters.

\begin{tabular}{|c|c|c|c|c|c|c|c|c|}
\hline \multirow{2}{*}{ M } & \multirow{2}{*}{ Structure } & \multicolumn{3}{|c|}{ Binding energy } & \multicolumn{2}{|c|}{ HOMO-LUMO gap } & \multicolumn{2}{|c|}{ Fermi energy } \\
\hline & & LDA (PWC) & GGA (PW91) & B3LYP/6-311G(d) ${ }^{\mathrm{a}}$ & LDA & GGA & LDA & GGA \\
\hline \multirow{3}{*}{$\mathrm{Mg}$} & Slab & -33.87 & -30.38 & -27.04 & 2.70 & 2.65 & -3.45 & -3.22 \\
\hline & Octagonal & -32.41 & -29.47 & -26.12 & 3.22 & 3.14 & -3.79 & -3.51 \\
\hline & Ladder & -32.18 & -29.03 & -25.63 & 2.09 & 2.08 & -3.60 & -3.35 \\
\hline \multirow{3}{*}{$\mathrm{Ca}$} & Slab & -38.50 & -34.63 & -32.37 & 3.14 & 2.89 & -2.00 & -1.81 \\
\hline & Octagonal & -34.91 & -31.70 & -29.56 & 1.15 & 1.35 & -1.86 & -1.75 \\
\hline & Ladder & -35.58 & -32.17 & -28.79 & 1.88 & 1.78 & -1.95 & -1.74 \\
\hline \multirow{3}{*}{$\mathrm{Sr}$} & Slab & -37.70 & -34.67 & - & 3.32 & 2.96 & -2.02 & -1.82 \\
\hline & Octagonal & -34.87 & -31.69 & - & 1.33 & 1.17 & -1.82 & -1.69 \\
\hline & Ladder & -35.30 & -33.69 & - & 1.96 & 1.92 & -1.87 & -1.69 \\
\hline \multirow{3}{*}{$\mathrm{Ba}$} & Slab & -39.83 & -36.15 & - & 3.65 & 3.38 & -2.01 & -1.78 \\
\hline & Octagonal & -36.48 & -33.31 & - & 1.67 & 1.48 & -1.72 & -1.61 \\
\hline & Ladder & -36.77 & -33.57 & - & 2.09 & 2.24 & -1.73 & -1.60 \\
\hline
\end{tabular}

${ }^{\mathrm{a}}$ From reference [40, 41].

TABLE 3: Binding energies, Fermi energies, and HOMO-LUMO gaps (in eV) for $(\mathrm{MO})_{5}$ clusters.

\begin{tabular}{|c|c|c|c|c|c|c|c|}
\hline \multirow{2}{*}{ M } & \multirow{2}{*}{ Structure } & \multicolumn{2}{|c|}{ Binding energy } & \multicolumn{2}{|c|}{ HOMO-LUMO gap } & \multicolumn{2}{|c|}{ Fermi energy } \\
\hline & & LDA (PWC) & GGA (PW91) & LDA & GGA & LDA & GGA \\
\hline \multirow{6}{*}{$\mathrm{Mg}$} & Ladder & -41.65 & -37.62 & 2.20 & 2.18 & -3.59 & -3.34 \\
\hline & Hexagonal & -41.65 & -37.62 & 2.21 & 2.20 & -3.58 & -3.34 \\
\hline & MgO-I & -41.52 & -37.57 & 2.25 & 2.19 & -3.59 & -3.34 \\
\hline & Decagonal & -41.08 & -37.41 & 3.36 & 3.30 & -3.79 & -3.47 \\
\hline & Chair & -42.87 & -38.57 & 2.30 & 2.24 & -3.54 & -3.28 \\
\hline & $\mathrm{MgO}-\mathrm{II}$ & -41.52 & -37.57 & 2.24 & 2.17 & -3.59 & -3.34 \\
\hline \multirow{6}{*}{$\mathrm{Ca}$} & Ladder & -45.53 & -41.19 & 1.91 & 1.82 & -1.92 & -1.70 \\
\hline & Hexagonal & -45.53 & -41.19 & 1.92 & 1.84 & -1.93 & -1.71 \\
\hline & $\mathrm{CaO}-\mathrm{I}$ & -45.11 & -40.88 & 1.87 & 1.75 & -1.91 & -1.70 \\
\hline & Decagonal & -43.19 & -39.37 & 1.99 & 1.92 & -1.52 & -1.35 \\
\hline & Chair & -47.74 & -43.01 & 2.00 & 1.90 & -2.16 & -1.90 \\
\hline & $\mathrm{CaO}-\mathrm{II}$ & -45.05 & -40.88 & 1.41 & 1.76 & -1.86 & -1.70 \\
\hline \multirow{5}{*}{$\mathrm{Sr}$} & Ladder & -44.92 & -42.81 & 1.91 & 1.89 & -1.81 & -1.63 \\
\hline & Hexagonal & -43.60 & -41.83 & 1.01 & 1.05 & -1.84 & -1.63 \\
\hline & SrO-I & -44.68 & -40.47 & 1.65 & 1.56 & -1.81 & -1.66 \\
\hline & Decagonal & -42.50 & -38.81 & 1.94 & 1.71 & -1.51 & -1.37 \\
\hline & SrO-II & -44.68 & -40.60 & 1.64 & 1.46 & -1.81 & -1.67 \\
\hline \multirow{5}{*}{$\mathrm{Ba}$} & Ladder & -46.54 & -47.44 & 1.97 & 2.14 & -1.64 & -1.52 \\
\hline & Hexagonal & - & -46.95 & - & 1.77 & - & -1.53 \\
\hline & $\mathrm{BaO}-\mathrm{I}$ & -46.42 & -42.37 & 1.98 & 1.82 & -1.69 & -1.57 \\
\hline & Decagonal & - & -43.07 & - & 1.86 & - & - \\
\hline & BaO-II & -46.41 & -42.35 & 1.95 & 1.80 & -1.68 & -1.56 \\
\hline
\end{tabular}

$\mathrm{SrO}$ and $\mathrm{BaO}$, the ladder form is found to be slightly preferred over the other forms. However, it may be noted that the energy differences are not very large for this stoichiometry.

$(\mathrm{MgO})_{5}$. Although $\mathrm{MgO}$ seems to prefer hexagonal structures, interestingly, in this case, the hexagonal fused ring optimizes to the ladder structure (Figure 4(a)). Similarly, the $\mathrm{MgO}-\mathrm{I}$ and MgO-II starting structures optimize to the same geometry, which is a hybrid of one hexagonal ring fused with two four-membered rings. The lowest energy structure for
$(\mathrm{MgO})_{5}$ is obtained from $(\mathrm{MgO})_{4}$ by capping an edge such that the capping atoms are bicoordinated, while the rest of the atoms are tricoordinated. The corresponding edge on $(\mathrm{MgO})_{4}$ opens up because of the increase in coordination number to three and consequent increase in ionic character. Similar is the case for the $(\mathrm{CaO})_{5}$ structures, except that LDA predicts two distinct structures, $\mathrm{CaO}-\mathrm{I}$ and $\mathrm{CaO}-\mathrm{II}$ (Figure 4(b)). For $(\mathrm{SrO})_{5}$ (Figure $\left.4(\mathrm{c})\right)$ and $(\mathrm{BaO})_{5}$ (Figure $4(\mathrm{~d})$ ), the ladder structures are preferred, and the chair structures could not be optimized. 


\begin{tabular}{|c|c|c|c|}
\hline \multirow{2}{*}{ Shape } & \multirow{2}{*}{ Initial geometry } & \multicolumn{2}{|c|}{ Optimized structures } \\
\hline & & LDA & GGA \\
\hline Ladder & & & \\
\hline Hexagona & & & \\
\hline MgO-I & & & \\
\hline Decagona & & & \\
\hline Chair & & & \\
\hline MgO-II & & & \\
\hline
\end{tabular}

(a)

\begin{tabular}{|c|c|c|}
\hline \multirow{2}{*}{ Shape } & \multirow{2}{*}{ Initial geometry } & Optimized structures \\
\hline & & GGA \\
\hline Ladder & & \\
\hline Hexago & & \\
\hline SrO-I & & \\
\hline Decagol & & \\
\hline SrO-II & & \\
\hline
\end{tabular}

(c)

\begin{tabular}{|l|c|c|c|}
\hline \multirow{2}{*}{ Shape } & \multirow{2}{*}{ Initial geometry } & \multicolumn{2}{|c|}{ Optimized structures } \\
\hline \multirow{2}{*}{ Hexagonal } & & LDA \\
\hline Mecagonal & & \\
\hline Chair & &
\end{tabular}

(b)

\begin{tabular}{|l|l|c|}
\hline \multirow{2}{*}{ Shape } & \multirow{2}{*}{ Initial geometry } & \multicolumn{2}{c|}{ Optimized structures* } \\
\cline { 2 - 3 } Ladder & & LDA \\
\hline Bexagonal & &
\end{tabular}

(d)

Figure 4: (a) Optimized structures from LDA and GGA calculations, along with the initial geometries for the (MgO) 5 system. (b) Optimized structures from LDA and GGA calculations, along with the initial geometries for the $(\mathrm{CaO})_{5}$ system. (c) Optimized structures from LDA and GGA calculations, along with the initial geometries for the $(\mathrm{SrO})_{5}$ system. (d) Optimized structures from LDA and GGA calculations, along with the initial geometries for the $(\mathrm{BaO})_{5}$ system. Dashes represent structures that did not optimize. 
TABle 4: Binding energies, HOMO-LUMO gaps, and Fermi energies (in eV) for $(\mathrm{MO})_{6}$ clusters.

\begin{tabular}{|c|c|c|c|c|c|c|c|}
\hline \multirow{2}{*}{ Structure } & \multicolumn{3}{|c|}{ Binding energy } & \multicolumn{2}{|c|}{ HOMO-LUMO gap } & \multicolumn{2}{|c|}{ Fermi energy } \\
\hline & LDA (PWC) & GGA (PW91) & B3LYP/6-311G(d) ${ }^{\mathrm{a}}$ & LDA & GGA & LDA & GGA \\
\hline Slab & -54.46 & -48.95 & -44.40 & 2.88 & 2.85 & -3.37 & -3.14 \\
\hline Hexagonal & -54.67 & -49.30 & -44.11 & 3.34 & 3.29 & -3.47 & -3.22 \\
\hline Ladder & -51.13 & -46.21 & - & 2.26 & 2.22 & -3.58 & -3.34 \\
\hline Slab & -60.34 & -54.31 & -51.01 & 2.95 & 2.78 & -1.95 & -1.74 \\
\hline Hexagonal & -59.90 & -54.05 & -50.70 & 2.98 & 2.86 & -1.96 & -1.74 \\
\hline Ladder & -55.48 & -50.21 & - & 1.93 & 1.86 & -1.90 & -1.69 \\
\hline Slab & -59.37 & -53.62 & - & 2.87 & 2.66 & -1.88 & -1.67 \\
\hline Hexagonal & -58.81 & -53.26 & - & 2.82 & 2.63 & -1.88 & -1.68 \\
\hline Ladder & -54.54 & -49.56 & - & 1.88 & 1.74 & -1.75 & -1.61 \\
\hline Slab & -60.89 & -55.14 & - & 3.02 & 2.89 & -1.79 & -1.58 \\
\hline Hexagonal & -60.53 & -55.00 & - & 3.06 & 2.89 & -1.83 & -1.60 \\
\hline Ladder & -56.29 & -51.32 & - & 1.87 & 1.82 & -1.56 & -1.45 \\
\hline
\end{tabular}

${ }^{\mathrm{a}}$ From reference $[40,41]$.

$(\mathrm{MO})_{6}$ Where $\mathrm{M}=\mathrm{Mg}, \mathrm{Ca}, \mathrm{Sr}, \mathrm{Ba}$. In this case, three structures, namely, slab, hexagonal, and ladder, were studied (Table 4).

Table 4 indicates that in the case of $\mathrm{MgO}$, the stacked hexagonal form is the most stable, and the slab structure is higher in energy by $0.21 \mathrm{eV}$. This energy difference increases to $0.57 \mathrm{eV}$ for the $(\mathrm{MgO})_{12}$ cluster $[22,23]$. For the other metal oxides, the slab structure is preferred. The $(\mathrm{MO})_{6}$ system is the first system for which both the slab structure and the hexagonal structure are possible, and we can make a comparison of the two. We observe that the $\mathrm{Mg}-\mathrm{O}$ bond distances in the terminal rings of $(\mathrm{MgO})_{6}$ are reduced when going from the rhombic (slab) to the hexagonal structure from $1.919 \AA$ in the former to $1.891 \AA$ in the latter. As for the ladder structures, the bond distance in the inner ring of the three-ring slab cluster $(2.123 \AA)$ is markedly elongated as compared to the terminal bond distance. As expected, the outer $\mathrm{Mg}-\mathrm{O}$ distance is closer to the molecular $1.822 \AA$, while the inner ring distance is closer to the $2.106 \AA$ lattice limit. Two distinctly different interplanar distances $(1.936 \AA$ and $1.898 \AA$ ) are also observed, depending on which atom, $\mathrm{Mg}$ or $\mathrm{O}$, sits on the terminal ring of the three-ring stack. It is larger when $\mathrm{O}$ is on the terminal ring because of the larger $\mathrm{O}^{2-}$ radius. The interplanar distance in the hexagonal stacked structure $(1.980 \AA)$ is much larger than the $\mathrm{Mg}-\mathrm{O}$ bond distance. The increased charge separation in the interior has only a minor effect on the terminal rings beyond that already seen for the double-ring $(\mathrm{MgO})_{4}$ system $(1.943 \AA)$.

For $\mathrm{CaO}$, we do not observe any $\mathrm{Ca}-\mathrm{O}$ bond compression with increasing number of atoms in the terminal rings; that is, the bond lengths do not vary too much when going from the slab $(2.108 \AA)$ to the hexagonal ring $(2.106 \AA)$ structure. There is, however, an interior ring expansion (2.290 $\AA$ ) in the slab structure, similar to the $\mathrm{MgO}$ system, due to increased polarization of the $\mathrm{Ca}-\mathrm{O}$ bond under the influence of the terminal rings. The terminal $\mathrm{Ca}-\mathrm{O}$ bond distance in the three-ring stack is observed to be the mean of the $2.405 \AA$ lattice value and the molecular $1.822 \AA$ distance [43].
The inner-ring Ca-O bond distance (2.288 $\AA$ ) is considerably closer to the bulk limit.

This behavior continues down the series. For $(\mathrm{SrO})_{6}$, the optimized interior $\mathrm{Sr}-\mathrm{O}$ bond distance $(2.422 \AA)$ is similar to the lattice value $(2.565 \AA)$, while the terminal ring distance $(2.245 \AA)$ is smaller and closer to the gas phase value (1.920 $\AA$ ). For $(\mathrm{BaO})_{6}$, the inner and outer $\mathrm{Ba}-\mathrm{O}$ bond distances are $2.564 \AA$ and $2.379 \AA$, respectively, compared to the gas phase and bulk values of $1.940 \AA$ and $2.762 \AA$, respectively. An interesting trend is also observed. As the atomic number of the metal ion increases, the interplanar distance in the stacked hexagonal ring approaches the $\mathrm{M}-\mathrm{O}$ distance in the ring, suggesting that spherical clusters become more important for the heavier alkaline earth metal oxides. For example, for $(\mathrm{MgO})_{6}$, the ring and interplanar distances are 1.891 and $1.980 \AA$, respectively. The corresponding distances are $2.118 \AA$ and $2.159 \AA(\mathrm{CaO}), 2.272 \AA$ and $2.290 \AA(\mathrm{SrO})$, and $2.422 \AA$ and $2.431 \AA(\mathrm{BaO})$.

The inner ring bond distance is also only slightly larger than the bulk value for the $(\mathrm{MgO})_{6}$ slab, and the deviation from the bulk value increases with increasing atomic number of the metal, suggesting a faster overall convergence to bulk properties for $\mathrm{MgO}$ clusters than for other alkaline metal oxide clusters.

Figure 5 depicts the optimized structures for the $(\mathrm{MO})_{6}$ clusters for different starting geometries.

3.2. Vibrational Frequencies. For small $\mathrm{MgO}$ clusters, the experimental [48] vibrational frequency at $640 \mathrm{~cm}^{-1}$ matches with a strong resonance observed at $651 \mathrm{~cm}^{-1}$ in the highresolution electron energy loss spectroscopy (HREELS) surface phonon spectrum of the solid surface $[49,50]$. The present calculations indicate that the vibrational frequency for this optically allowed stretching motion of oxygen atoms perpendicular to the surface of the $(\mathrm{MgO})_{6}$ hexagonal cluster is at $691 \mathrm{~cm}^{-1}$ (intensity $=512 \mathrm{~km} \mathrm{~mol}^{-1}$ ), while for the slab structure, this band is at $740 \mathrm{~cm}^{-1}$ (intensity $=445 \mathrm{~km} \mathrm{~mol}^{-1}$ ). For the $(\mathrm{MgO})_{12}$ nanocluster, the corresponding values 


\begin{tabular}{|c|c|c|c|}
\hline \multirow{2}{*}{ Shape } & \multirow{2}{*}{ Initial geometry } & \multicolumn{2}{|c|}{ Optimized structures } \\
\cline { 2 - 4 } Slab & LDA & GGA \\
\hline Ladder & &
\end{tabular}

(a)

\begin{tabular}{|l|c|c|c|}
\hline \multirow{2}{*}{ Shape } & \multirow{2}{*}{ Initial geometry } & \multicolumn{2}{|c|}{ Optimized structures } \\
\cline { 3 - 4 } Hexagonal & & LDA & GGA \\
\hline \multirow{2}{*}{ Ladder } & &
\end{tabular}

(c)

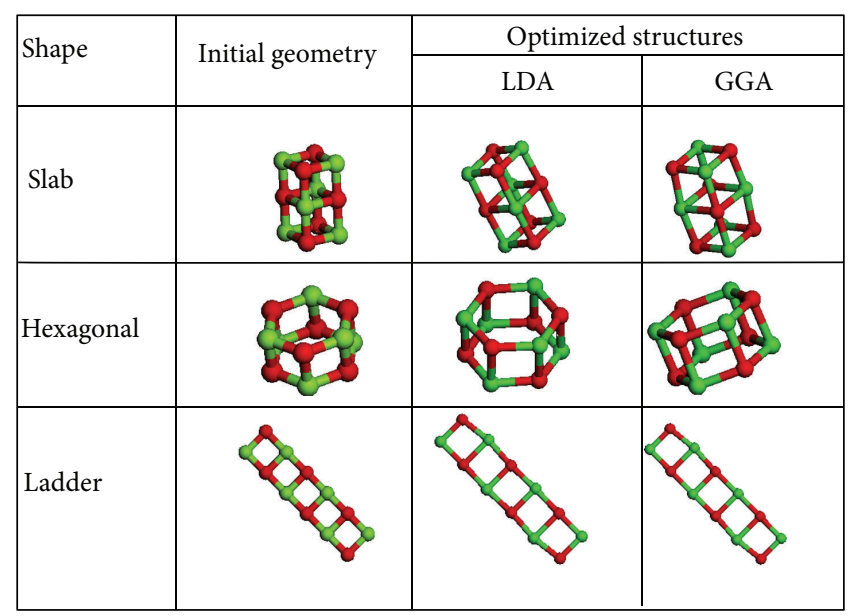

(b)

\begin{tabular}{|l|c|c|}
\hline \multirow{2}{*}{ Shape } & \multirow{2}{*}{ Initial geometry } & \multicolumn{2}{|c|}{ Optimized structures } \\
\hline \multirow{2}{*}{ Slab } & & LDA \\
\hline Hexagonal & &
\end{tabular}

(d)

FIGURE 5: (a) Optimized structures from LDA and GGA calculations, along with the initial geometries for the (MgO) ${ }_{6}$ system. (b) Optimized structures from LDA and GGA calculations, along with the initial geometries for the $(\mathrm{CaO})_{6}$ system. (c) Optimized structures from LDA and GGA calculations, along with the initial geometries for the $(\mathrm{SrO})_{6}$ system. (d) Optimized structures from LDA and GGA calculations, along with the initial geometries for the $(\mathrm{BaO})_{6}$ system.

$[22,23]$ are $657 \mathrm{~cm}^{-1}$ (intensity $=1132 \mathrm{~km} \mathrm{~mol}^{-1}$ ) (hexagonal) and $677 \mathrm{~cm}^{-1}$ (intensity $=705 \mathrm{~km} \mathrm{~mol}^{-1}$ ) $(\mathrm{slab})$.

3.3. Electronic Structures. As noted previously, the preferred geometry for the $(\mathrm{MgO})_{6}$ cluster is tubular, which becomes more stable than the rectangular bulk-like cluster due to stabilization of the occupied levels. The isosurfaces of the HOMO and LUMO reveal that these comprise mainly the $2 \mathrm{p}$ orbitals of oxygen and $3 \mathrm{~s}$ and $3 \mathrm{p}$ orbitals of $\mathrm{Mg}$, respectively, but the LUMO also has an oxygen $3 \mathrm{~s}$ component (see Figure 6). Thus, the anion-centered nature of the HOMO indicates that its energy depends strongly on the $\mathrm{O}-\mathrm{O}$ distances. In the hexagonal structure, the $\mathrm{O}-\mathrm{O}$ distance is $3.45 \AA$, compared to $2.86 \AA$ for the rectangular cluster. The smaller anion-anion repulsion in the nanotube stabilizes the HOMO, increasing the HOMO-LUMO gap.

The electronic density of states (DOS) near the Fermi level for the two structures is shown in Figure 7. The separation of bands for the hexagonal structure is about $3.3 \mathrm{eV}$, which is higher than that obtained for the slab cluster $(2.9 \mathrm{eV})$, but considerably smaller than the value of $4.8 \mathrm{eV}$ computed for bulk $\mathrm{MgO}$.

The DOS plots for the nanotube and cube-like structure are qualitatively similar, but one important difference is noticeable. In the hexagonal structure, there is greater involvement of the $\mathrm{Mg}^{2+}$ ion $3 \mathrm{~d}$ orbitals near the Fermi level, although the population analysis reveals that the $\mathrm{Mg}$ electron configurations in the two are similar $\left(3 s^{0.34} 2 \mathrm{p}^{6} 3 \mathrm{p}^{0.46} 3 \mathrm{~d}^{0.26}\right.$ for the hexagonal structure and $3 s^{0.36} 2 \mathrm{p}^{6} 3 \mathrm{p}^{0.45} 3 \mathrm{~d}^{0.26}$ for the terminal slab ions). The peak height for the slab structure is also smaller. The computed electron configuration of the magnesium ion differs from the expected $2 p^{6}$. The $3 \mathrm{~s}, 3 \mathrm{p}$, and $3 \mathrm{~d}$ orbitals are occupied, leading to a formal charge on $\mathrm{Mg}$ closer to one than the expected two.

The densities of states were also calculated for the slab structures of the other $(\mathrm{MO})_{6}$ systems. These are shown in Figure 8. 
TABLE 5: Bond lengths $(\AA)$ and binding energies (eV) per MgO unit for different stoichiometries of $(\mathrm{MO})_{n}$.

\begin{tabular}{|c|c|c|c|c|}
\hline $\mathrm{MO}$ & Number of units & Preferred structure & $\begin{array}{l}\text { Binding energy } \\
\text { per molecule }\end{array}$ & $R$ \\
\hline \multirow{6}{*}{$\mathrm{MgO}$} & 1 & Linear & -3.69 & 1.743 \\
\hline & 2 & Rhombus & -6.75 & 1.858 \\
\hline & 3 & Hexagonal & -7.78 & 1.819 \\
\hline & 4 & Slab & 8.47 & 1.936 \\
\hline & 5 & Chair & -8.57 & $1.788-1.967$ \\
\hline & 6 & Hexagonal & -9.08 & $1.891,1.980$ \\
\hline \multirow{6}{*}{$\mathrm{CaO}$} & 1 & Linear & -5.08 & 1.818 \\
\hline & 2 & Rhombus & -8.01 & 2.005 \\
\hline & 3 & Ladder & -8.53 & $1.952-2.294$ \\
\hline & 4 & Slab & -9.63 & 2.126 \\
\hline & 5 & Chair & -9.55 & $1.940-2.204$ \\
\hline & 6 & Slab & -10.06 & $2.108-2.289$ \\
\hline \multirow{6}{*}{$\mathrm{SrO}$} & 1 & Linear & -5.59 & 1.928 \\
\hline & 2 & Rhombus & -8.19 & 2.140 \\
\hline & 3 & Ladder & -8.54 & $2.074-2.389$ \\
\hline & 4 & Slab & -9.38 & $2.249,2.256$ \\
\hline & 5 & Ladder & -9.07 & $2.204-2.341$ \\
\hline & 6 & Slab & -9.90 & $2.238-2.422$ \\
\hline \multirow{6}{*}{$\mathrm{BaO}$} & 1 & Linear & -6.55 & 2.031 \\
\hline & 2 & Rhombus & -8.75 & 2.277 \\
\hline & 3 & Ladder & -8.98 & $2.189-2.512$ \\
\hline & 4 & Slab & -9.97 & $2.413-2.417$ \\
\hline & 5 & Ladder & -9.31 & $2.205-2.532$ \\
\hline & 6 & Slab & -10.15 & $2.374-2.566$ \\
\hline
\end{tabular}
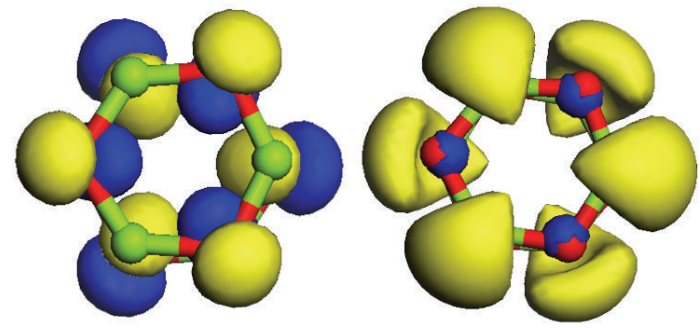

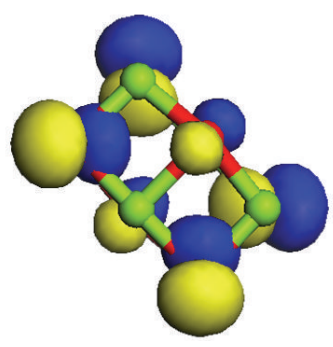

HOMO

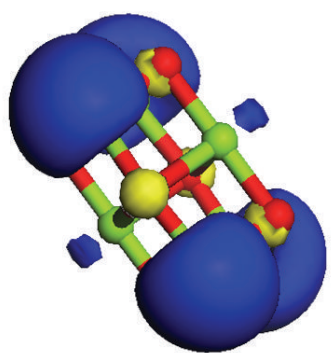

LUMO
Figure 6: Isosurfaces (isovalue $=0.03 \mathrm{Ha}$ ) of the HOMOs and LUMOs of the $(\mathrm{MgO})_{6}$ hexagonal and cubic clusters.

It can be seen from Figure 8 that the involvement of $\mathrm{d}$ orbitals increases with increasing atomic number of the metal ion. Indeed, the participation of $\mathrm{d}$ orbitals increases from 0.263 in the terminal atoms of the $\mathrm{MgO}$ slab to 0.406 in $\mathrm{CaO}$, 0.715 in $\mathrm{SrO}$, and 0.835 for $\mathrm{BaO}$. This happens at the expense of the $\mathrm{p}$ orbital population, so that the overall charge on the metal ion remains close to +1 . For the inner metal ions, the participation of $\mathrm{d}$ orbitals is a little smaller. The additional electron comes from a $2 p$ orbital of oxygen, and the oxygen atoms have electron configurations close to $1 s^{2} 2 s^{2} 2 p^{5}$ in all cases. Another noticeable feature is that, while the bands are sharp for the other $(\mathrm{MO})_{6}$ systems, they are broad for $(\mathrm{CaO})_{6}$. In fact, $\mathrm{CaO}$ appears to exhibit some anomalous behavior, as the Mulliken charge on $\mathrm{Ca}$ is slightly higher than that calculated for the metal ions in the other metal oxides.

\section{Discussion}

The bond lengths and total energy per molecule for the lowest energy structures are given in Table 5. The binding energy for a single $\mathrm{MgO}$ molecule is quite low in comparison to other clusters. The bond length $(1.743 \AA)$ is, however, small. As the cluster size increases, the bond lengths and binding energies increase in an oscillatory manner. The bond length is elongated to $1.882 \AA$ in the most favorable structure of $(\mathrm{MgO})_{2}$, which is a rhombus. The binding energy per molecule also increases significantly, though this value is still much smaller than that for larger clusters. The lowest energy structure for $(\mathrm{MgO})_{3}$ is planar and ring type, with each atom being bicoordinated. The $\mathrm{Mg}-\mathrm{O}$ bond length in this case is shorter compared with the $(\mathrm{MgO})_{2}$ cluster, and there is a significant increase in the binding energy. The bond angles about oxygen ions are smaller than those about magnesium 


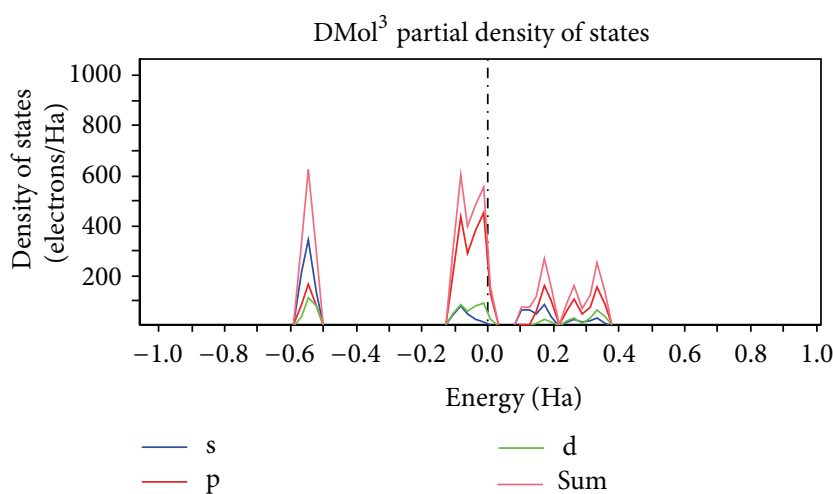

(a)

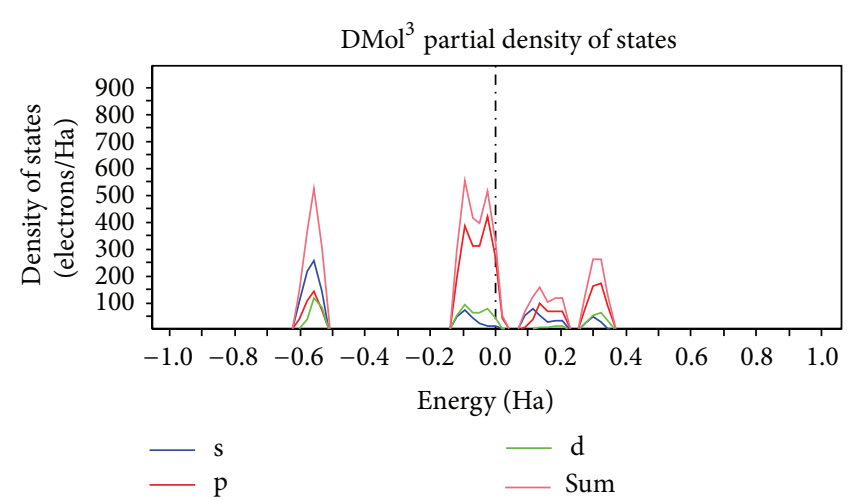

(b)

Figure 7: Calculated partial densities of states for the (a) hexagonal and (b) slab (MgO) ${ }_{6}$.

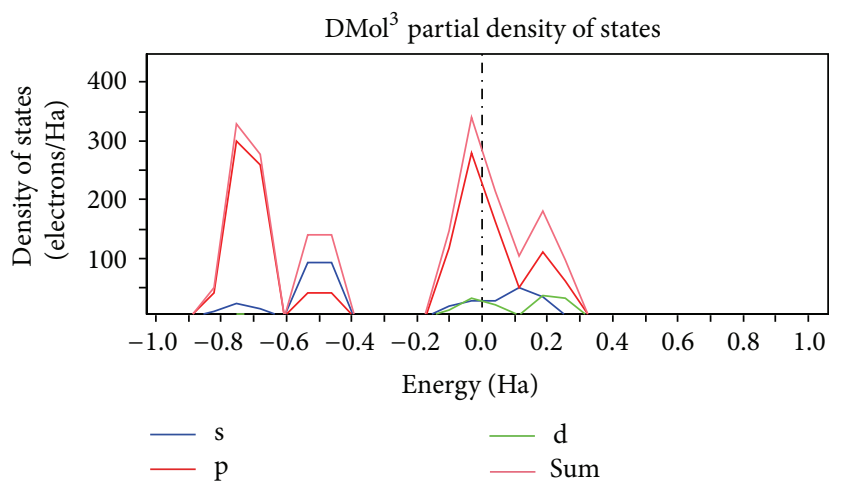

(a)

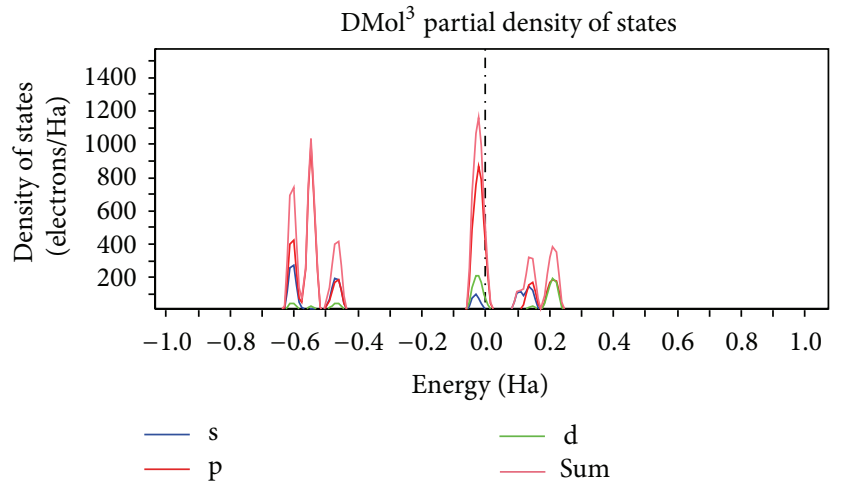

(b)

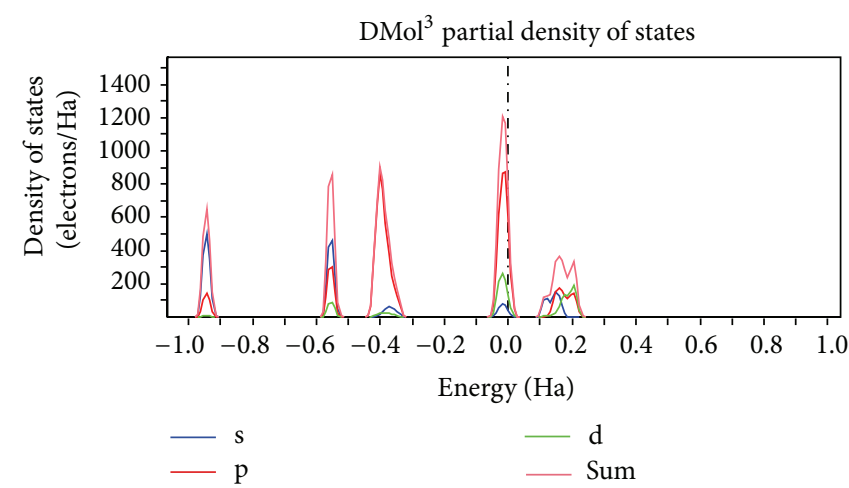

(c)

Figure 8: Calculated partial densities of states for the $(\mathrm{a})(\mathrm{CaO})_{6}$, (b) $(\mathrm{SrO})_{6}$, and (c) $(\mathrm{BaO})_{6}$ slabs.

ions, but the $\mathrm{MgO}$ bond lengths remain the same within both planar structures. In some of the structures, notably the chair structures, a large variation in $\mathrm{M}-\mathrm{O}$ distances within the cluster is discernible from Table 5.

The increased stability of slab structures (both $n=4$ and $n=6$ ) is obvious from the binding energies per molecule for all systems (except $(\mathrm{MgO})_{n}$, for which the hexagonal ringbased structures turn out to be more stable), in agreement with previous studies [29, 32, 40, 41]. For $n>3$, our results that ring structures lie higher in energy are in contrast with reported results [17-20], in which $n=4$ and 5 were reported to have ring structures. For all $(\mathrm{MO})_{4}$, the slab structures are preferred over the octagonal ring and ladder structures. However, while for all the other $(\mathrm{MO})_{4}$ system, the ring structure is the least preferred, for $(\mathrm{MgO})_{4}$ it is preferred over the ladder structure. It may be noted that the ring structure undergoes considerable distortion in all cases except for $\mathrm{MgO}$.

An important observation from the optimized threedimensional isomers is the chair-type structures of $(\mathrm{MgO})_{n}$ 
clusters. This is very interesting, as it indicates the existence of some covalent bonding in $\mathrm{MgO}$ clusters similar to covalently bonded silicon, although $\mathrm{MgO}$ is considered to be ionic in the bulk. Covalent bonding in alkaline-earth oxides increases [51] as one goes from $\mathrm{MgO}$ to $\mathrm{CaO}, \mathrm{SrO}$, and $\mathrm{BaO}$ due to increasing involvement of $\mathrm{d}$ orbitals in bonding (Figure 8). While in bulk this is negligible for $\mathrm{MgO}$, a reduction in the bond lengths in clusters could be responsible for the increased covalent character.

In the case of $(\mathrm{CaO})_{n}$, there is a consistent preference for slab-shaped structures, but the stability difference between the most stable and the second most stable structure is always small. Thus, hexagonal rings are slightly more stable than the slab-shaped structures in the case of $(\mathrm{MgO})_{n}$, whereas the opposite is true for $(\mathrm{CaO})_{n}$. Consequently, we consider whether this possible trend continues, that is, toward increased relative stability of the slab structures relative to the hexagonal. Whereas the overall patterns of the $\mathrm{Sr}$ and $\mathrm{Ba}$ compounds are similar to $\mathrm{Ca}$, we note in the case of $(\mathrm{BaO})_{6}$ the lesser difference in stability between the slab and hexagonal ring-based isomers. Based on these observations, it can be concluded that there is no definite trend towards increasing preference for the slab shape with increasing atomic number on the metal for the small alkaline earth oxide clusters.

The similar values of the calculated Mulliken charges, approximately +1 on the metal ions in the various metal oxide clusters, make it difficult to assign an electronic cause for the slight preference for hexagonal structures in the case of $\mathrm{MgO}$ and slab structures for the other metal oxides. This leads us to believe that it is a packing effect rather than an electronic one. As stated in the sections above, due to the small cation size in $\mathrm{MgO}$, the $\mathrm{Mg}-\mathrm{O}$ bond is short, and, consequently, the four-membered ring in the slab structure is too strained. In order to accommodate the small cation and the large anion in the four-membered ring, the $\mathrm{Mg}-\mathrm{O}$ bond length increases, leading to a weakening of the bonding and consequent instability. On the other hand, the octagonal ring structure is too open and is hence not favored for any of the metal oxides. This leaves the six-membered ring as a compromise for $\mathrm{MgO}$ systems.

An alternate explanation for the preference for the sixmembered ring structure in the case of $\mathrm{MgO}$ could be the existence of aromaticity. In order to quantify aromaticity, we used the nucleus-independent chemical shift (NICS) method proposed by Schleyer et al. [52]. The NICS values were calculated at the center of the six-membered ring (NICS $(0)$ ) and at a plane $1 \AA$ above it (NICS(1)) and compared with the corresponding values calculated for benzene. In this method, negative NICS values indicate aromaticity and positive values antiaromaticity. We had earlier $[53,54]$ concluded that the NICS(1) value is the best measure of aromaticity for benzene. The calculated NICS(1) value for benzene is -10.84 , whereas the corresponding values for $(\mathrm{MgO})_{3}$ and $(\mathrm{CaO})_{3}$ ring structures are -2.05 and 2.75 , respectively, clearly indicating that the $\mathrm{MgO}$ ring is about $20 \%$ aromatic, while the $\mathrm{CaO}$ ring is antiaromatic, accounting for the increased stability of the $\mathrm{MgO}$ ring.

\section{Conclusions}

An important finding of the present study is that hexagonal tube-like structures are preferred for $(\mathrm{MgO})_{n}$ clusters, while slab-like structures are preferred for the other alkaline earth metal oxide clusters. Explanations based on ionic size effects and aromaticity have been proposed in this work. It is gratifying to note that experimental observations of mass spectra $[14,15,48,55]$ indicate the existence and stabilities of such stacked hexagonal rings, at least for small gas-phase clusters of $\mathrm{MgO}$. Other experimental and theoretical [22, $23,56]$ studies also provide evidence for the existence and stabilities of $\mathrm{MgO}$ nanotubes.

An outstanding result of the present study is the similar stabilities of the hexagonal-ring-based structures and the rock-salt-like slab-shaped isomers. While this observation is important as such and contradicts the exclusive nature of the latter structural shapes proposed previously [17-20], it is noteworthy how the stability ordering changes as the metal atomic number increases among the alkaline earth elements. In the case of $(\mathrm{MgO})_{n}$, the hexagonal-ring-based structure is the more stable one, although the energy difference between the two structures is small. Going to $(\mathrm{CaO})_{n}$, the situation is reversed in that the slab structure prevails. For $(\mathrm{SrO})_{n}$, the trend towards increasing stabilization of the slab structures continues, and the slab structure is evidently the more stable one. For $(\mathrm{BaO})_{n}$, the slab structure is still the preferred one, but to a lesser extent. An explanation based on simple packing arguments has been proposed to explain the variation in relative stabilities. Aromaticity in the $(\mathrm{MgO})_{3}$ ring also accounts for its stability.

It is difficult to find experimental verification for our results, as neutral clusters are difficult to study experimentally. Their structures are usually inferred indirectly from the mass spectra of ionized clusters, the more abundant species being interpreted as the more stable. However, the results from such studies on alkaline earth metal oxides are contradictory and depend on the process of formation of the clusters. Two conclusions, however, result from these studies. Firstly, for small clusters, hexagonal stacked rings are preferred for $(\mathrm{MgO})_{n}^{+}$, but these give way to rock-salt cubic structures for large values of $n$. Secondly, $(\mathrm{CaO})_{n}^{+}$ fragmentation clusters are found for both even values of $n$ and when $n$ is a multiple of 3 . These results suggest that the basic cluster-building blocks are different for the two materials, as observed from the present calculations. The results of the experimental studies and our calculations can be reconciled if we assume that the neutral stoichiometric $(\mathrm{MgO})_{n}$ and $(\mathrm{CaO})_{n}$ clusters show structural differences: the basic building block is an $(\mathrm{MgO})_{3}$ hexagonal fragment in the case of $\mathrm{MgO}$ and $\mathrm{a}(\mathrm{CaO})_{3}$ rectangular $2 \times 3$ (or double-chain) fragment for $\mathrm{CaO}$, as the one found in the present studies. This difference is just a packing effect due to the larger overlap repulsion between anions in $\mathrm{MgO}$ since the cation size is very small and is also due to the aromaticity of the $(\mathrm{MgO})_{3}$ ring.

These experiments also suggest that the hexagonal ring and rectangular slab structures are topologically equivalent. Deformation along one of the directions orthogonal to the rings stack transforms it into the slab structure. As noted 
earlier, this intense vibration mode for $(\mathrm{MgO})_{6}$ occurs at a low wavenumber $\left(691 \mathrm{~cm}^{-1}\right)$. Thus, experimental knowledge of abundance of masses alone cannot distinguish between the two structures, and sophisticated calculations such as the present ones can only decide the relative stabilities. Our earlier studies $[22,23]$ on the $(\mathrm{MgO})_{12}$ cluster had indicated that the $(\mathrm{MgO})_{12}$ nanotube, consisting of four stacked hexagonal $(\mathrm{MgO})_{3}$ rings, is more stable than the bulk-like cubic structure by $0.48 \mathrm{eV}$. Moreover, the calculated energy barrier for the rearrangement of the cubic structure to the tube was found to be only $0.13 \mathrm{eV}$, and hence the two structures are easily interconvertible.

\section{Conflict of Interests}

The authors declare no conflict of interests with any financial organization regarding the material presented in the paper.

\section{Acknowledgments}

The authors thank the Council of Scientific and Industrial Research (CSIR) for financial support (Grant no. 01(2554)/12/EMR-1). Ritu Gaba and Upasana Issar thank the CSIR and the University Grants Commission (UGC), respectively, for Senior Research Fellowships.

\section{References}

[1] A. Jain, V. Kumar, M. Sluiter, and Y. Kawazoe, "First principles studies of magnesium oxide clusters by parallelized Tohoku University Mixed-Basis program TOMBO," Computational Materials Science, vol. 36, no. 1-2, pp. 171-175, 2006.

[2] N. Sharma and R. Kakkar, "Recent advancements in warfare agents/metal oxides surface chemistry and their simulant studies," Advanced Materials Letters, 2013.

[3] P. N. Kapoor, A. K. Bhagi, R. S. Mulukutla, and K. J. Klabunde, Dekker Encyclopedia of Nanoscience \& Technology, Marcel Dekker, New York, NY, USA, 2004.

[4] A. Khaleel, P. N. Kapoor, and K. J. Klabunde, "Nanocrystalline metal oxides as new adsorbents for air purification," Nanostructured Materials, vol. 11, no. 4, pp. 459-468, 1999.

[5] J. Heyd, J. E. Peralta, and G. E. Scuseria, "Energy band gaps and lattice parameters evaluated with the Heyd-Scuseria-Ernzerhof screened hybrid functional," Journal of Chemical Physics, vol. 123, no. 17, Article ID 174101, 8 pages, 2005.

[6] S. Utamapanya, K. J. Klabunde, and J. R. Schlup, "Nanoscale metal oxide particles/clusters as chemical reagents," Chemistry of Materials, vol. 3, pp. 175-181, 1991.

[7] O. Koper, Y. X. Li, and K. J. Klabunde, "Destructive adsorption of chlorinated hydrocarbons on ultrafine (nanoscale) particles of calcium oxide," Chemistry of Materials, vol. 5, no. 4, pp. 500505, 1993.

[8] Y. X. Li and K. J. Klabunde, "Nano-scale metal oxide particles as chemical reagents. Destructive adsorption of a chemical agent simulant, dimethyl methylphosphonate, on heat-treated magnesium oxide," Langmuir, vol. 7, no. 7, pp. 1388-1393, 1991.

[9] Y.-X. Li, J. R. Schlup, and K. J. Klabunde, "Fourier transform infrared photoacoustic spectroscopy study of the adsorption of organophosphorus compounds on heat-treated magnesium oxide," Langmuir, vol. 7, no. 7, pp. 1394-1399, 1991.
[10] R. C. Whited, C. J. Flaten, and W. C. Walker, "Exciton thermoreflectance of $\mathrm{MgO}$ and CaO," Solid State Communications, vol. 13, no. 11, pp. 1903-1905, 1973.

[11] I. S. Elfimov, S. Yunoki, and G. A. Sawatzky, "Possible path to a new class of ferromagnetic and half-metallic ferromagnetic materials," Physical Review Letters, vol. 89, no. 21, Article ID 216403, 4 pages, 2002.

[12] B. Nagappa and G. T. Chandrappa, "Nanocrystalline $\mathrm{CaO}$ as adsorbent to remove COD from paper mill effluent," Journal of Nanoscience and Nanotechnology, vol. 7, no. 3, pp. 1039-1042, 2007.

[13] F. Jin, Y. Liu, and M. D. Christopher, "Barium strontium oxide coated carbon nanotubes as field emitters," Applied Physics Letters, vol. 90, no. 14, Article ID 143114, 3 pages, 2007.

[14] W. A. Saunders, "Structural dissimilarities between small II-VI compound clusters: $\mathrm{MgO}$ and $\mathrm{CaO}$," Physical Review B, vol. 37, no. 11, pp. 6583-6586, 1988.

[15] W. A. Saunders, "Molecules and clusters," Zeitschrift für Physik D, vol. 12, pp. 601-603, 1989.

[16] T. P. Martin and T. Bergmann, "Mass spectra of Ca-O and BaO clusters," The Journal of Chemical Physics, vol. 90, no. 11, pp. 6664-6667, 1989.

[17] P. J. Ziemann and A. W. Castleman, "Mass-spectrometric study of the formation, evaporation, and structural properties of doubly charged MgO clusters," Physical Review B, vol. 44, no. 12, pp. 6488-6499, 1991.

[18] P. J. Ziemann and A. W. Castleman, "Structures and bonding properties of calcium oxide clusters inferred from mass spectral abundance patterns ," The Journal of Physical Chemistry, vol. 96, no. 11, pp. 4271-4276, 1992.

[19] P. J. Ziemann and A. W. Castleman Jr., "Mass spectrometric study of MgO clusters produced by the gas aggregation technique," Zeitschrift für Physik D, vol. 20, pp. 97-99, 1991.

[20] P. J. Ziemann and A. W. Castleman Jr., "Stabilities and structures of gas phase MgO clusters," Journal of Chemical Physics, vol. 94, no. 1, pp. 718-728, 1991.

[21] M. Gutowski, P. Skurski, X. Li, and L.-S. Wang, " $(\mathrm{MgO})_{\mathrm{n}}{ }^{-}(n=$ 1-5) clusters: multipole-bound anions and photodetachment spectroscopy," Physical Review Letters, vol. 85, no. 15, pp. 31453148, 2000.

[22] R. Kakkar, P. N. Kapoor, and K. J. Klabunde, “Theoretical study of the adsorption of formaldehyde on magnesium oxide nanosurfaces: size effects and the role of low-coordinated and defect sites," The Journal of Physical Chemistry B, vol. 108, no. 47, pp. 18140-18148, 2004.

[23] R. Kakkar, P. N. Kapoor, and K. J. Klabunde, "First principles density functional study of the adsorption and dissociation of carbonyl compounds on magnesium oxide nanosurfaces," Journal of Physical Chemistry B, vol. 110, no. 51, pp. 25941-25949, 2006.

[24] R. Dong, X. Chen, X. Wang, and W. Lu, "Structural transition of hexagonal tube to rocksalt for $(\mathrm{MgO})_{3 n}, 2 \leq n \leq 10$," Journal of Chemical Physics, vol. 129, no. 4, Article ID 044705, 5 pages, 2008.

[25] M. Srnec and R. Zahradník, "Small group IIa-VIa clusters and related systems: a theoretical study of physical properties, reactivity, and electronic spectra," European Journal of Inorganic Chemistry, vol. 2007, no. 11, pp. 1529-1543, 2007.

[26] M. Wilson, "Stability of small MgO nanotube clusters: predictions of a transferable ionic potential model," The Journal of Physical Chemistry B, vol. 101, no. 25, pp. 4917-4924, 1997. 
[27] M. Wilson, P. A. Madden, N. C. Pyper, and J. H. Harding, "Molecular dynamics simulations of compressible ions," Journal of Chemical Physics, vol. 104, no. 20, pp. 8068-8081, 1996.

[28] E. De La Puente, A. Aguado, A. Ayuela, and J. M. López, "Structural and electronic properties of small neutral $(\mathrm{MgO})_{n}$ clusters," Physical Review B, vol. 56, no. 12, pp. 7607-7614, 1997.

[29] M.-J. Malliavin and C. Coudray, "Ab initio calculations on $(\mathrm{MgO})_{n},(\mathrm{CaO})_{n}$, and $(\mathrm{NaCl})_{n}$ clusters $(n=1-6)$," Journal of Chemical Physics, vol. 106, no. 6, pp. 2323-2330, 1997.

[30] J. M. Recio, R. Pandey, A. Ayuela, and A. B. Kunz, "Molecular orbital calculations on $(\mathrm{MgO})_{n}$ and $(\mathrm{MgO})_{\mathrm{n}}{ }^{+}$clusters $(n=1-$ 13)," The Journal of Chemical Physics, vol. 98, no. 6, pp. 47834792, 1993.

[31] J. M. Recio and R. Pandey, "Ab initio study of neutral and ionized microclusters of MgO," Physical Review A, vol. 47, no. 3, pp. 2075-2082, 1993.

[32] A. Aguado and J. M. López, "Structures and stabilities of $\mathrm{CaO}$ and $\mathrm{MgO}$ clusters and cluster ions: an alternative interpretation of the experimental mass spectra," The Journal of Physical Chemistry B, vol. 104, no. 35, pp. 8398-8405, 2000.

[33] B. Delley, "An all electron numerical method for solving the local density functional for polyatomic molecules," Journal of Chemical Physics, vol. 92, no. 1, pp. 508-517, 1990.

[34] B. Delley, "Analytic energy derivatives in the numerical local density functional approach," Journal of Chemical Physics, vol. 94, no. 11, pp. 7245-7250, 1991.

[35] B. Delley, "Fast calculation of electrostatics in crystals and large molecules," The Journal of Physical Chemistry, vol. 100, no. 15, pp. 6107-6110, 1996.

[36] B. Delley, "From molecules to solids with the $\mathrm{DMol}^{3}$ approach," Journal of Chemical Physics, vol. 113, no. 18, pp. 7756-7764, 2000.

[37] J. P. Perdew, J. A. Chevary, S. H. Vosko et al., "Atoms, molecules, solids, and surfaces: applications of the generalized gradient approximation for exchange and correlation," Physical Review $B$, vol. 46, no. 11, pp. 6671-6687, 1992.

[38] J. P. Perdew and Y. Wang, "Accurate and simple analytic representation of the electron-gas correlation energy," Physical Review B, vol. 45, no. 23, pp. 13244-13249, 1992.

[39] R. Kakkar, R. Grover, and P. Gahlot, "Density functional study of the properties of isomeric aminophenylhydroxamic acids and their copper (II) complexes," Polyhedron, vol. 25, no. 3, pp. 759766, 2006.

[40] F. Bawa and I. Panas, "Competing pathways for $\mathrm{MgO}, \mathrm{CaO}, \mathrm{SrO}$, and $\mathrm{BaO}$ nanocluster growth," Physical Chemistry Chemical Physics, vol. 4, pp. 103-108, 2002.

[41] Á. Vibók and G. J. Halász, "Parametrization of complex absorbing potentials for time-dependent quantum dynamics using multi-step potentials," Physical Chemistry Chemical Physics, vol. 3, pp. 3042-3047, 2001.

[42] S. Veliah, R. Pandey, Y. S. Li, J. M. Newsam, and B. Vessal, “Density functional study of structural and electronic properties of cube-like MgO clusters," Chemical Physics Letters, vol. 235, no. 1-2, pp. 53-57, 1995.

[43] K. P. Huber and G. Herzberg, Molecular Spectra and Molecular Structure, IV. Constants of Diatomic Molecules, van Nostrand Reinhold, New York, NY, USA, 1979.

[44] M. C. Day and J. Selbin, Theoretical Inorganic Chemistry, chapter 4, Reinhold, New York, NY, USA; Chapman \& Hall, London, UK, 1962.

[45] D. J. Driscoll, W. Martir, J. X. Wang, and J. H. Lunsford, "Formation of gas-phase methyl radicals over magnesium oxide,"
Journal of the American Chemical Society, vol. 107, no. 1, pp. 5863, 1985.

[46] T. Ito and J. H. Lunsford, "Synthesis of ethylene and ethane by partial oxidation of methane over lithium-doped magnesium oxide," Nature, vol. 314, pp. 721-722, 1985.

[47] T. Ito, J. X. Wang, C. H. Lin, and J. H. Lunsford, "Oxidative dimerization of methane over a lithium-promoted magnesium oxide catalyst," Journal of the American Chemical Society, vol. 107, no. 18, pp. 5062-5068, 1985.

[48] D. Van Heijnsbergen, G. Von Helden, G. Meijer, and M. A. Duncan, "Infrared resonance-enhanced multiphoton ionization spectroscopy of magnesium oxide clusters," Journal of Chemical Physics, vol. 116, no. 6, pp. 2400-2406, 2002.

[49] P. A. Cox and A. A. Williams, "HREELS studies of simple ionic solids," Journal of Electron Spectroscopy and Related Phenomena, vol. 39, pp. 45-48, 1986.

[50] V. E. Henrich and P. A. Cox, The Surface Science of Metal Oxides, Cambridge University Press, Cambridge, Mass, USA, 1994.

[51] G. Pacchioni, C. Sousa, F. Illas, P. S. Bagus, and F. Parmigiani, "Measures of ionicity of alkaline-earth oxides from the analysis of ab initio cluster wave functions," Physical Review B, vol. 48, no. 16, pp. 11573-11582, 1993.

[52] P. V. R. Schleyer, C. Maerker, A. Dransfeld, H. Jiao, and N. J. R. Van Eikema Hommes, "Nucleus-independent chemical shifts: a simple and efficient aromaticity probe," Journal of the American Chemical Society, vol. 118, no. 26, pp. 6317-6318, 1996.

[53] R. Kakkar and C. Singh, "Theoretical study of the kojic acid structure in gas phase and aqueous solution," International Journal of Quantum Chemistry, vol. 111, no. 15, pp. 4318-4329, 2011.

[54] R. Kakkar, M. Bhandari, and R. Gaba, "Tautomeric transformations and reactivity of alloxan," Computational and Theoretical Chemistry, vol. 986, pp. 14-24, 2012.

[55] G. W. Wang and H. Hattori, "Reaction of adsorbed carbon monoxide with hydrogen on magnesium oxide," Journal of the Chemical Society, Faraday Transactions 1, vol. 80, pp. 1039-1047, 1984.

[56] G. Bilalbegović, "Structural and electronic properties of $\mathrm{MgO}$ nanotube clusters," Physical Review B, vol. 70, no. 4, Article ID 045407, 6 pages, 2004. 

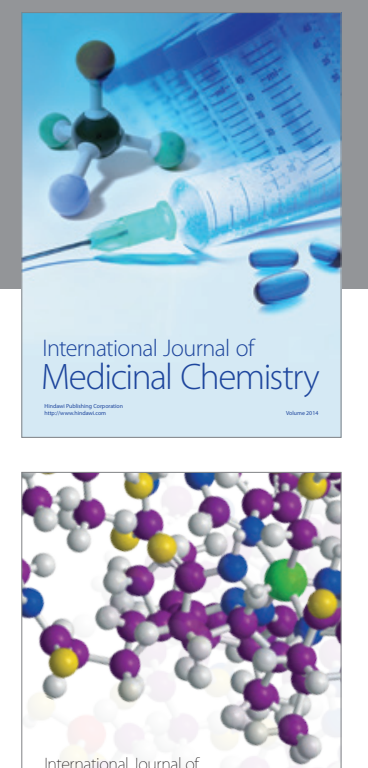

\section{Carbohydrate} Chemistry

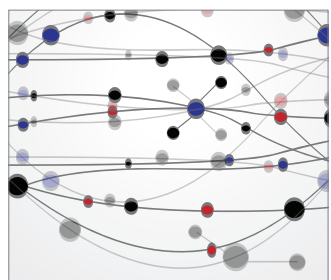

The Scientific World Journal
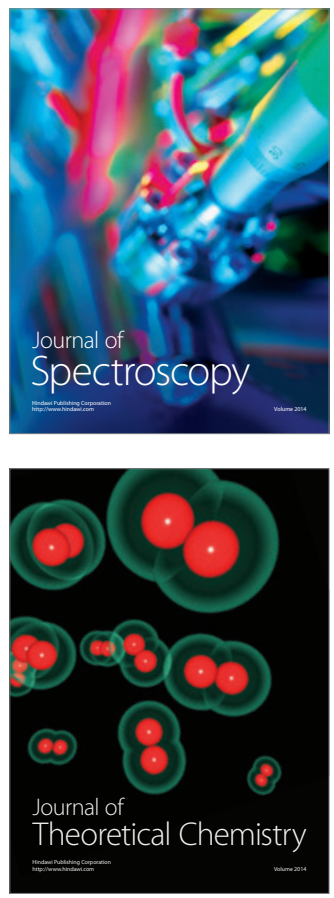
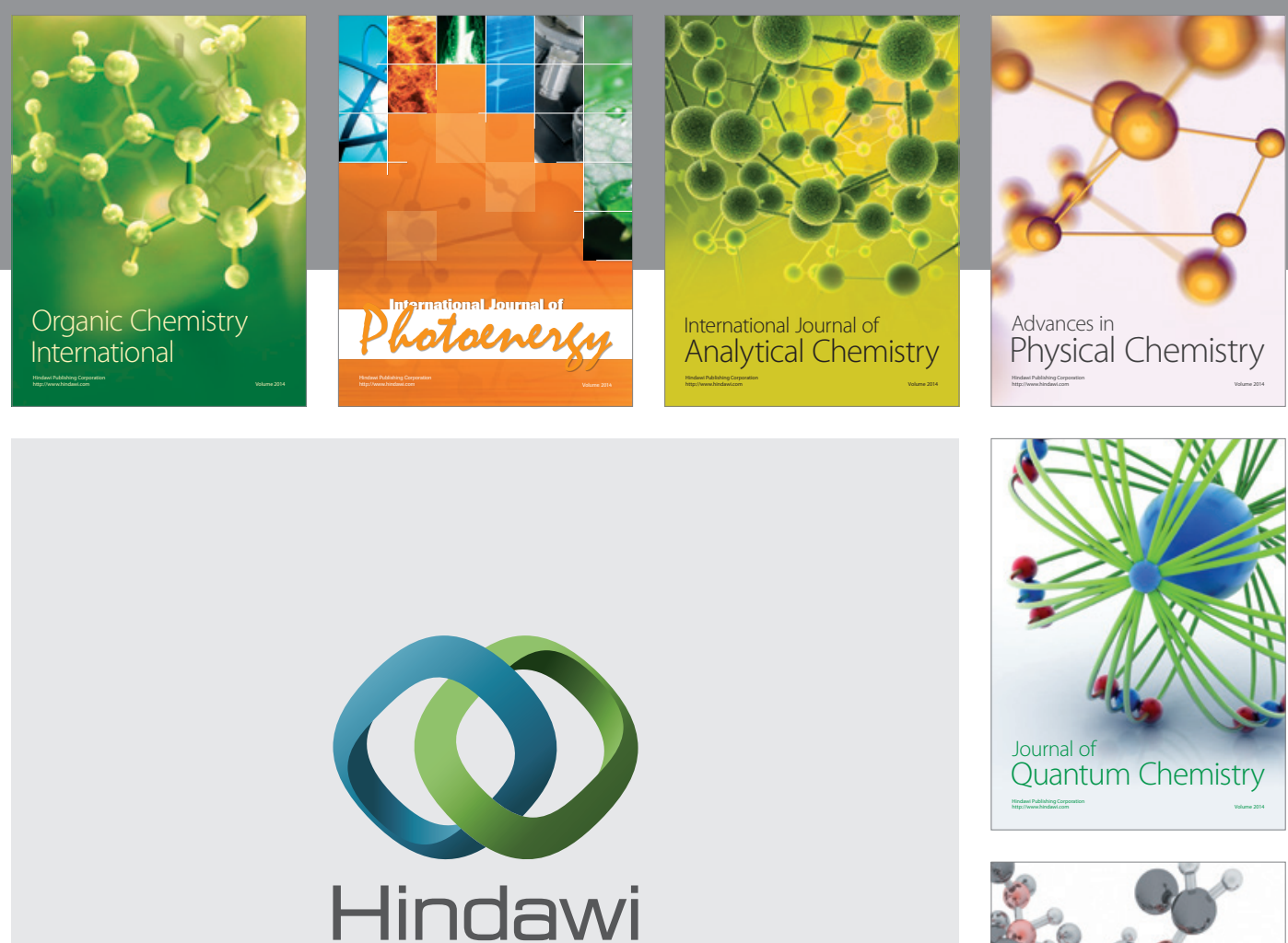

Submit your manuscripts at

http://www.hindawi.com

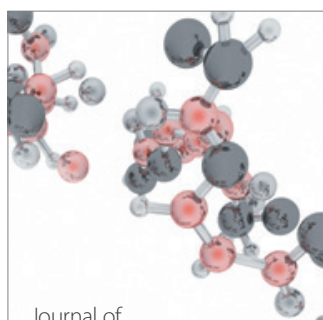

Analytical Methods

in Chemistry

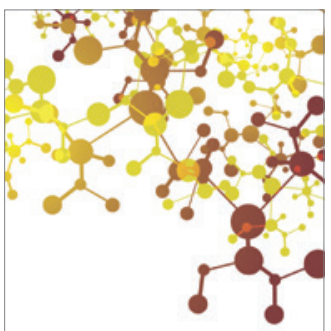

Journal of

Applied Chemistry

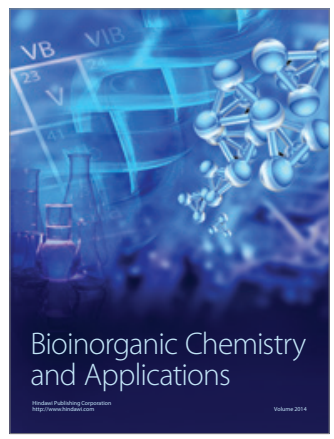

Inorganic Chemistry
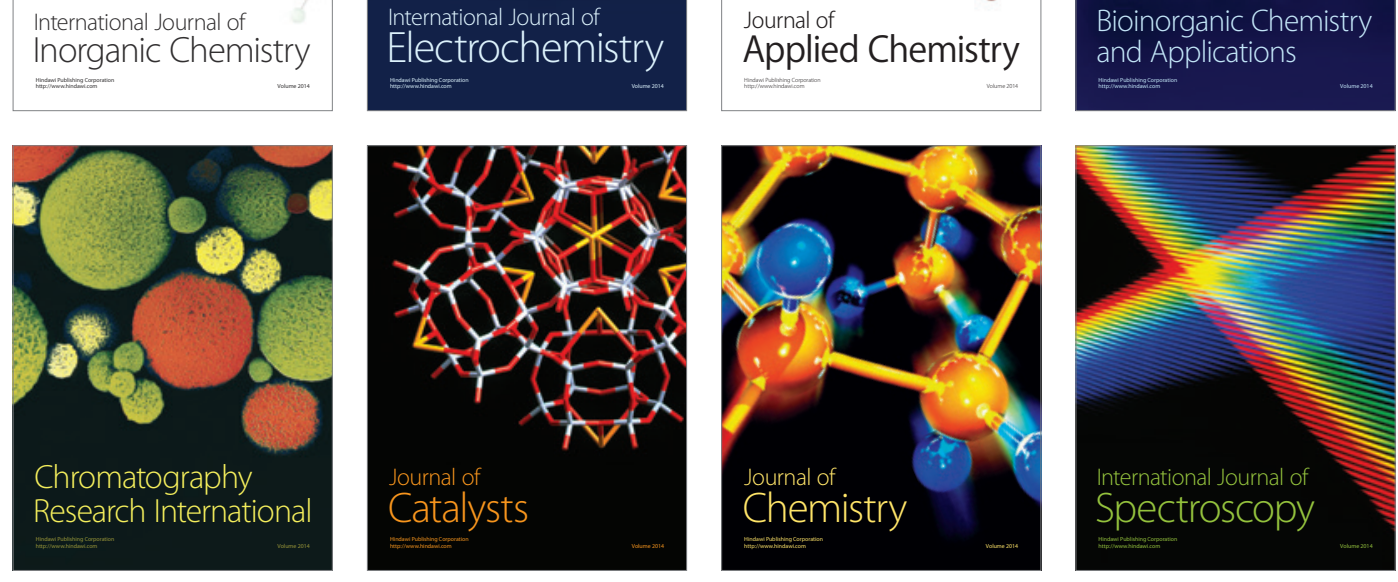